\title{
Anatomical Position of Four Different Transobturator Mesh Implants for Female Anterior Prolapse Repair
}

\author{
Anatomische Lage von 4 transobturatorischen Mesh-Implantaten zur Korrektur \\ des vorderen Kompartiments
}

Authors

Affiliations
F. Lenz ${ }^{1}$, S. Doll ${ }^{2}$, C. Sohn ${ }^{3}$, K. A. Brocker ${ }^{3}$

${ }^{1}$ Department of Obstetrics and Gynecology, Hetzelstift Hospital, Neustadt an der Weinstraße

${ }^{2}$ Institute of Anatomy and Cell Biology, University of Heidelberg, Heidelberg

${ }^{3}$ Department of Obstetrics and Gynecology, University of Heidelberg, Heidelberg
Key words

- mesh repair

- arcus tendineus fasciae pelvis

white line

- endopelvic fascia

- pelvic floor anatomy

Schlüsselwörter

- Mesh-Repair

- Arcus tendineus fascia pelvis

- White Line

- endopelvine Faszie

- Beckenbodenanatomie

\section{received 12.2.2013 \\ revised 19.5.2013 \\ accepted 6.6.2013}

Bibliography

Dol http://dx.doi.org/

10.1055/s-0033-1350700

Geburtsh Frauenheilk 2013; 73 :

1035-1041 @ Georg Thieme

Verlag KG Stuttgart · New York ·

ISSN 0016-5751

\section{Correspondence}

Dr. Kerstin A. Brocker

University of Heidelberg

Department of Obstetrics

and Gynecology

Voßstraße 9

69115 Heidelberg

kerstin.brocker@

med.uni-heidelberg.de

\section{Abstract}

$\nabla$

Purpose: Polypropylene mesh implants are frequently used for pelvic floor reconstruction in women. Yet they vary in size and fixation. The purpose of this study is to compare four mesh products with regard to their anatomical positioning and functionality within the pelvic floor, to determine whether each mesh fits equally well in a female cadaver.

Methods: One female pelvis was dissected, opening the retropubic space exposing the endopelvic fascia and demonstrating the arcus tendineus fasciae pelvis (ATFP). Anatomical parameters were measured before and after implanting four meshes via the transobturator approach.

Results: The anterior fixation of the ATFP was found to be $5 \mathrm{~mm}$ lateral to the symphysis in this cadaver. The endopelvic fascia covered $54.6 \mathrm{~cm}^{2}$. The obturator nerve was located $35 \mathrm{~mm}$ from the white line. The distance of the proximal and lateral points of mesh fixation from the ischial spine or ATFP varied from 0 to $25 \mathrm{~mm}$. The meshes varied in size and anatomical positioning.

Conclusion: These observations demonstrate the necessity of developing optimally sized meshes and appropriate introducer techniques that can provide sufficient vaginal support. Surgeons, furthermore, need profound knowledge of anatomy, the patient's pelvic floor defect and the meshes available on the market.

\section{Zusammenfassung \\ $\nabla$}

Vaginale Polypropylenimplantate werden zur Rekonstruktion des weiblichen Beckenbodens angewendet. Jedoch variieren die verschiedenen, auf dem Markt angebotenen Produkte in Form, Größe und Verankerungstechniken. Gegenstand dieser Studie ist es, 4 Produkte in eine weibliche Leiche zu implantieren, diese hinsichtlich der anatomischen Position und Funktionalität im Beckenboden zu untersuchen und festzustellen, ob die 4 Produkte in gleicher Weise in den Beckenboden dieser Leiche passen. Es wurde eine weibliche Frischleiche seziert. Die endopelvine Faszie wurde freigelegt und der Arcus tendineus fascia pelvis (ATFP) dargestellt. Vier auf dem Markt verfügbare transobturatorische Mesh-Implantate wurden nacheinander implantiert entsprechend der Herstellerangaben. Anatomische Parameter wurden vor und nach Mesh-Implantation festgehalten. Der anteriore Fixationspunkt des ATFP zeigte sich in dieser Leiche $5 \mathrm{~mm}$ lateral der Symphyse. Die endopelvine Faszie bedeckte einen Bereich von $54,6 \mathrm{~cm}^{2}$. Der N. obturatorius wurde $35 \mathrm{~mm}$ entfernt vom ATFP dargestellt. Die Entfernung der proximalen und lateralen Fixationspunkte der Mesh-Implantate von der Spina ischiadica oder dem ATFP variierten von 0 bis $25 \mathrm{~mm}$. Die Implantate unterscheiden sich in Größe und Lage zu anatomischen Strukturen. Zusammenfassend demonstrieren diese Ergebnisse die Notwendigkeit der Entwicklung von Implantaten optimaler Größe. Darüber hinaus benötigen die Anwender dieser Implantate detailliertes Wissen über die anatomischen Verhältnisse ihrer Patientin und auch der auf dem Markt erhältlichen Produkte, um ein zufriedenstellendes postoperatives Ergebnis zu ermöglichen. 

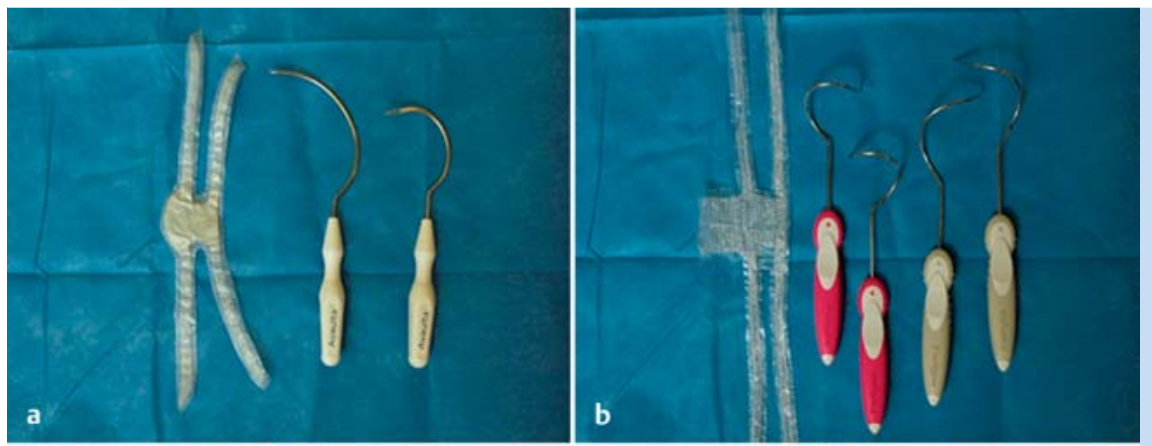

Fig. 1 a to d Picture of all four of the evaluated meshes and their introducer needles.

a Avaulta;

b Perigee;

c Prolift anterior;

d Seratom.
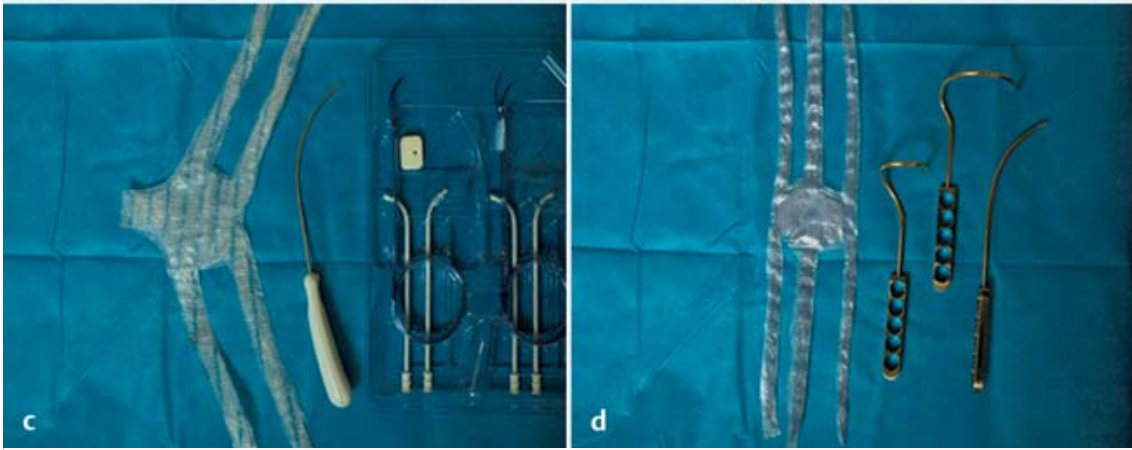

\section{Introduction}

$\nabla$

Symptomatic pelvic organ prolapse (POP) is a common disorder in women. Several surgical approaches are possible to minimize a woman's discomfort. Yet the recurrence rates for classical POP surgeries, e.g. anterior colporrhaphy, are high, between 20 and $30 \%$. This led to the call for alternative methods, which have since been developed employing alloplastic material [1-5]. The procedure referred to as mesh repair was invented in which the mesh is inserted either transvaginally or abdominally and fixed to the pelvis by sutures. However, elaborate preparations are necessary both to display the anatomical structures and to achieve optimal fixation of the implant $[6,7]$. The introduction of a surgical approach via a transobturator route marked a turning point in POP reconstruction.

Recently several companies have developed numerous alloplastic implants (meshes) of varying size, texture or form of application. Their overall aim, though, is to repair POP by reconstructing the endopelvic fascia via the transobturator route if there is a level I defect (destroyed sacrouterine ligaments) or level II defect (torn endopelvic fascia near the arcus tendineus fasciae pelvis) of the pelvic floor [1,8-11]. The importance of the endopelvic fascia and its variability in size and destruction when treating women with pelvic organ prolapse has numerously been described by several authors [6,10,12-14]. Most meshes are unifilar, macroporous and low in weight [15].

Implants that are predominantly polypropylene are currently used. The material has proven its physiological compatibility in the field of hernia surgery [1]. At the time this study was conducted, four frequently used products available for prolapse repair of the anterior compartment were Avaulta ${ }^{\circledR}$ Anterior BioSynthetic Support System, Perigee ${ }^{\mathrm{TM}}$ Prolapse Repair System, Gynecare Prolift System and Seratom ${ }^{\circledR}$ Prolapse Repair System ( Fig. 1) [16]. They vary in size and shape and in their introducer needles. The latter are used to pierce the pathway through pelvic structures to suspend the implant. Tension-free insertion of the mesh has reduced the recurrence rate of cystoceles and recto- celes compared to conventional procedures, such as anterior and posterior colporrhaphy $[2,17,18]$.

In order to support the bladder and vagina in the anterior compartment, the purpose of a mesh is to provide a supportive layer. Ideally this layer functions as the anterior vaginal wall, the connective tissue that attaches it to the pelvic bones through the pubovaginal portion of the levator ani muscle, and the uterosacral and cardinal ligaments forming the tendinous arch of the pelvic fascia [19]. The arcus tendineus fasciae pelvis (ATFP) extends from the posterior surface of the pubic bone to the ischial spine and the uterosacral ligament $[10,20]$. For repairing anterior compartment defects, the most important structures are the endopelvic fascia (EF), the ATFP, the ischial spine and the sacrospinal/ sacrotuberal ligaments [20]. The endopelvic or pubocervical fascia is connective tissue attached to the lateral pelvic wall at the ATFP (white line). It fastens to the vagina sideways and supports the bladder. Further cranially the EF condenses to the cardinal, vesicouterine and uterosacral ligaments as cervical anchoring. In summary, the EF, as the supporting structure, and the pelvic muscles, as sustaining structures, are responsible for pelvic organ positioning [20]. The ATFP extends from the posterior surface of the pubis body to the ischial spine and the uterosacral ligament $[10,20]$.

Alternative surgical methods became available with the introduction of alloplastic material into POP surgery and the development of the transobturator route [21]. The classical surgical techniques do not seem to be an alternative to the use of polypropylene meshes in combination with an anterior enterocele transobturator approach for recurrent cystoceles, symptomatic traction cystoceles and vaginal stump prolapse. Although mesh implants can satisfactorily reconstruct the above mentioned defects they are often associated with numerous complications such as dyspareunia, pelvic pain syndromes, shrinking or mesh erosion and full understanding of the complications' origin has not yet been developed $[15,22,23]$. Unfortunately, the up-to-date literature does not offer any distinct guidelines with regard to mesh size or specific type of introducer needle for achieving optimal long-term 
effectiveness [24]. As a matter of fact, the decision as to which mesh to implant has until now been based mostly on the surgeon's opinion and experience with certain mesh kits. Yet our hypothesis that led to this study was that not every mesh fits appropriately into every pelvic floor, for the anatomical situation and the prolapse are different in each patient.

Therefore, the aim of this study is, on one hand, to describe the actual anatomical position of the four different polypropylene implants after reconstruction of the anterior compartment of the pelvic floor in one cadaver, and, on the other, to predict the probable advantages or disadvantages of each.

\section{Materials and Methods}

\section{$\nabla$}

The pelvis of one fresh female cadaver (70 years of age, postmenopausal, without visible scars or post-surgical pelvic floor trauma) was dissected in the lithotomy position. Only one cadaver was used in this study to describe the positioning of all four frequently used meshes in one pelvic floor in order to examine the authors' assumption that not all meshes fit one pelvic floor equally well. The urogynecological surgeon implanting the mesh into the cadaver had equal experience with all four products. The complete process of this study was accompanied and documented by the affiliated Institute of Anatomy and Cell Biology.

Points of interest were the perforation spots created by the introducer needles in the lateral pelvic wall. From their location, we evaluated the maximum depth of a mesh implant as well as the final position of a mesh in the anterior compartment in relation to the reconstruction area of the EF. The dissection was started medially by opening the retropubic space and removing fat from the paravesical space to demonstrate the pelvic floor. After dissection of the ATFP, EF, obturator nerve, ischial spine and sacrospinous ligament, a 150-ml catheter was inserted into the bladder to demarcate it from the EF. This was followed by measuring the distances between ischial spine and ischial spine (ischial spine distance), and the length of the white line from the inner surface of the pubic bone to the most medial tip of the ischial spine. These distances define the boundaries of the EF underlying the bladder and making it possible to determine its area. In other words, the calculation of the area of the endopelvic fascia was performed by multiplying the length from the retropubic insertion of the endopelvic fascia up to the ischial spine with the interspinal distance (length $\times$ width) [25].

Chosen for examination were four meshes that were frequently used at the time this study was conducted. These were Avaulta ${ }^{\circledR}$ Anterior BioSynthetic Support System, the Perigee ${ }^{\mathrm{TM}}$ Prolapse Repair System, the Gynecare Prolift System and Seratom ${ }^{\circledR}$ Prolapse Repair System, which were used for anterior prolapse repair ( Table 1). The meshes actually used were purchased on the market. The order in which the meshes were implanted was chosen randomly. All the implants were implanted using the original technique and introducer needles as described in the instruction manuals. Therefore a midline incision in the anterior vaginal wall was made starting $3 \mathrm{~cm}$ below the urethral meatus, near the bladder neck and extending to the vaginal cuff. The vaginal mucosa was dissected from the bladder laterally to the internal obturator muscle at the level of the bladder neck and proximally to the ischial spine on both sides. The point through which the introducer needles perforated the internal obturator muscle was documented during implantation. After implantation, the final position of each mesh was determined by measuring the distance from it to the relevant anatomical structures.

The Perigee ${ }^{\mathrm{TM}}$ Prolapse Repair System was implanted first. We began by palpating the edge of the ischiopubic ramus commencing at the superior level of the vaginal incision, continuing along the edge of the bone towards the level of the clitoris, denoting where the long adductor tendon inserts into the pubic ramus. Superior skin incisions were placed approximately at this location and lateral to the edge of the bone. This procedure was repeated on the cadaver's contralateral side and confirmed that both marks were in a straight line at the approximate level of the clitoris. Afterwards the edge of the inferior pubic ramus was palpated until it ended at the bottom of the obturator foramen, and inferior skin incisions were placed on both sides. This point was approximately $3 \mathrm{~cm}$ below and $2 \mathrm{~cm}$ lateral to the superior marks.

Table 1 Product information for all implanted meshes.

\begin{tabular}{|c|c|c|c|c|}
\hline Company & Gynecare & AMS & Bard & Serag Wiessner \\
\hline Product name & Prolift & $\begin{array}{l}\text { Perigee (ant.) } \\
\text { Apogee (post.) }\end{array}$ & Avaulta & Seratom E PA \\
\hline Material & PP & PP & PP & PP/PGACL \\
\hline Weight (g) & $\begin{array}{l}1.3 \text { (anterior) } \\
0.7 \text { (posterior) }\end{array}$ & $\begin{array}{l}1.5 \text { (Perigee) } \\
1.0 \text { (Apogee) }\end{array}$ & 0.8 (anterior) & $1.3 ; 0.6^{*}$ \\
\hline $\mathrm{m}^{2}$-weight $\left(\mathrm{g} / \mathrm{m}^{2}\right)$ & 45 & 55 & 100 & $65 ; 20^{*}$ \\
\hline \multicolumn{5}{|l|}{ Thickness } \\
\hline - Net arms (mm) & 0.4 & 0.7 & 0.5 & 0.6 \\
\hline - Net body (mm) & 0.4 & 0.5 & 0.4 & 0.5 \\
\hline \multicolumn{5}{|l|}{ Size of pores } \\
\hline - Plain $\left(\mathrm{mm}^{2}\right)$ & 7 & 6 & 1 & 6 \\
\hline - Width (mm) & 3 & 3 & 2 & 2 \\
\hline - Height $(\mathrm{mm})$ & 3 & 3 & 1 & 4 \\
\hline Share of pores in body (\%) & 60 & 50 & 50 & 60 \\
\hline \multicolumn{5}{|l|}{ Bending stiffness } \\
\hline > Lengthwise (mg) & 4 & 5 & 43 & 16 \\
\hline - Crosswise (mg) & 6 & 5 & 49 & 32 \\
\hline Bursting stiffness (N) & 190 & 180 & 180 & 150 \\
\hline \multicolumn{5}{|l|}{ Tear Resistance } \\
\hline - Lengthwise (N) & 60 & 80 & 70 & 90 \\
\hline
\end{tabular}

PP = polypropylene; PGACL = polyglycolic-acid-caprolaction; $\mathrm{N}=$ Newton; * = after resorption of resorbable mesh threads. 


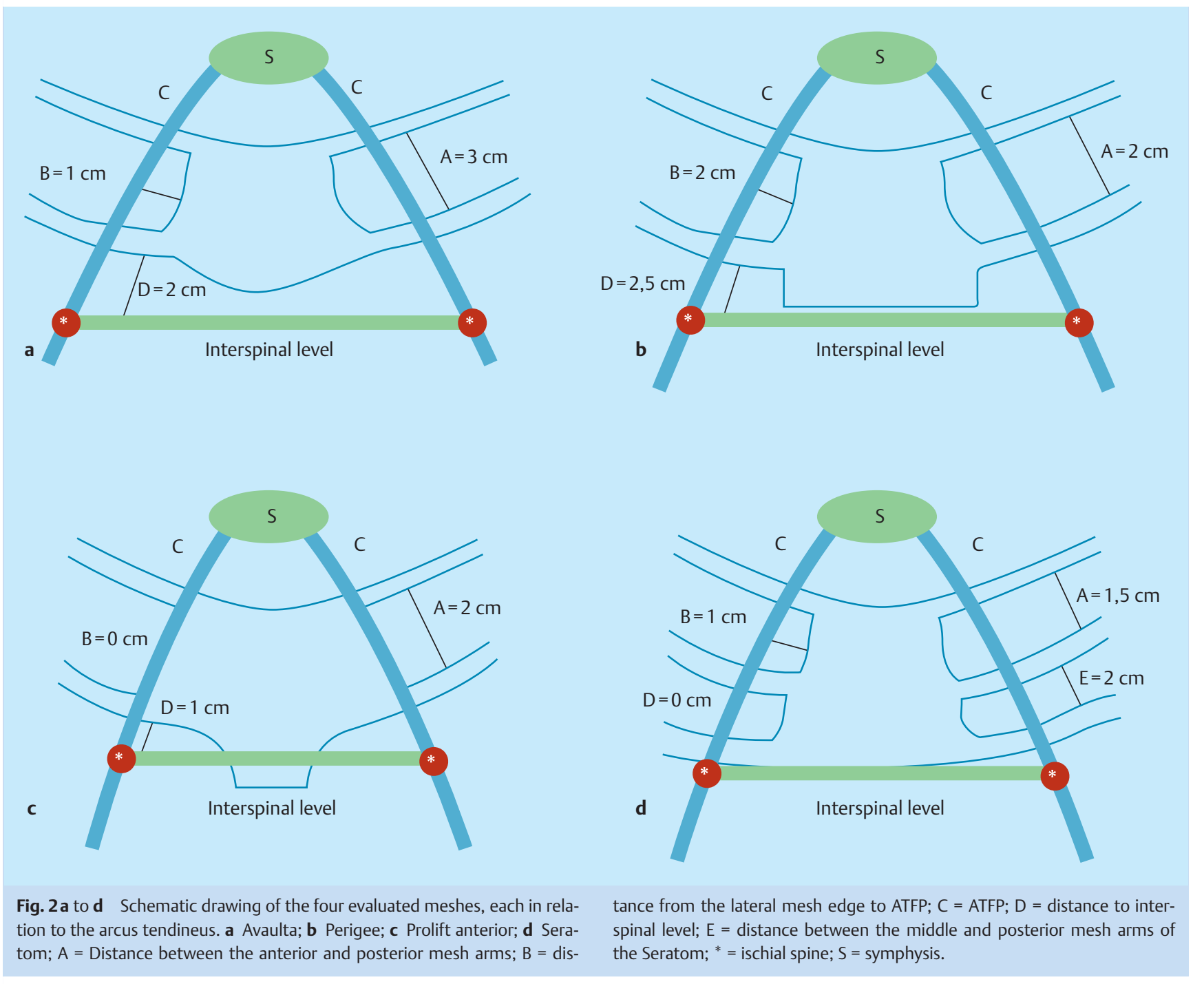

To place the anterior mesh arm, the tip of the needle was pointed perpendicular to the skin towards the superior incision. While advancing the right superior needle, the left hand thumb was first placed on the outer curve of needle to control the perforation through the obturator membrane and muscle and then pushed the needle through obturator muscle and membrane. The needle shaft and handle was positioned at a $45^{\circ}$ angle to the patient's vertical axis and close to the patient's body. Now the handle of the needle was rotated, moving the needle's tip and curve around the posterior surface of the ischial pubic ramus towards the vaginal incision and the index finger placed intravaginally. After perforating the internal obturator membrane at the level of the ATFP, the distances to the ischial spine were measured. Now the needle's tip was directed towards the vaginal incision until it extended through it. The superior connector that had been pre-attached to the sheath covering the mesh was attached to the superior needle exiting the vaginal incision. After the connector had been attached to the needle, it was rotated back through the skin incision, pulling the connector and associated mesh insertion sheath with the graft into position. This was repeated on the contralateral side. The superior insertion was followed by the placement of the inferior mesh arm, for which the needle's tip was pointed perpendicular to the skin towards the inferior incision; the needle's orientation was parallel to patient's vertical axis. While advancing the right inferior needle, the left hand thumb was at first placed on the outer curve of needle to control the perforation through obturator membrane and muscle, and it then pushed the needle through obturator muscle and membrane. The needle's shaft and handle were positioned parallel to the patient's vertical axis and close to the patient's body. After perforation of the internal obturator membrane at the level of the ATFP near the ischial spine, the distance to the ischial spine was documented. By rotating the needle's handle the needle's tip curved towards the proximal end of the vaginal incision. The needle passage and graft connection were repeated on the cadaver's contralateral side. The mesh now supported the bladder and was in its final position. The several distances to the ATFP and ischial spine were measured. After documentation the implant was carefully removed so as not to destroy any anatomical structures.

This procedure was followed by the analogous implantation of the Avaulta ${ }^{\circledR}$ Anterior BioSynthetic Support System, the Gynecare Prolift System and the Seratom ${ }^{\circledR}$ Prolapse Repair System according to their commercial instructions. The final implant was the Seratom ${ }^{\circledR}$ Prolapse Repair System. This unifilar partly absorbable polypropylene mesh is, in contrast to the other products, fixed at 

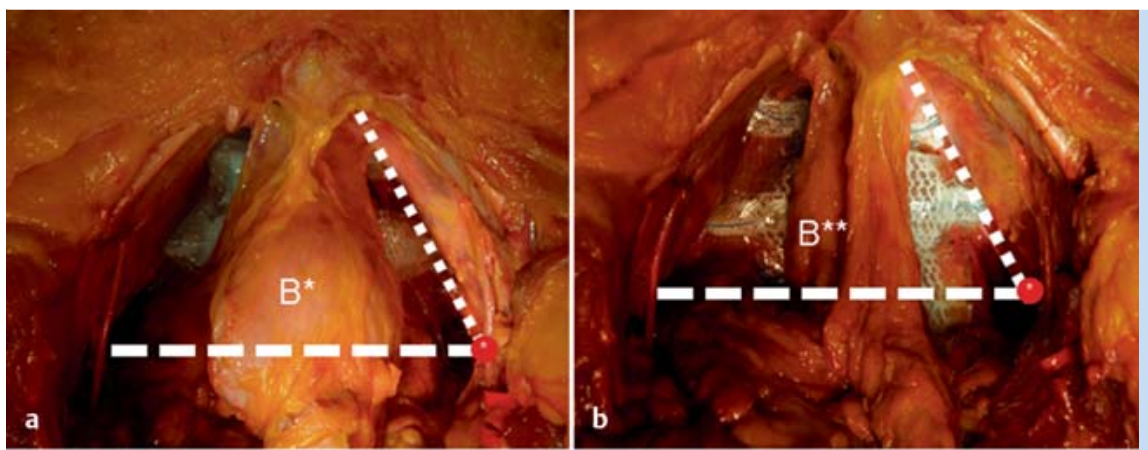

Fig. 3 a to $\mathbf{d}$ In situ picture of the meshes after implantation.

a Avaulta mesh beneath filled bladder;

b Perigee;

c Prolift anterior;

d Seratom;

$\mathrm{B}^{*}=$ bladder filled with water;

$\mathrm{B}^{* *}=$ bladder not filled;

small dotted line = ATFP;

$*$ = ischial spine;

large dotted line $=$ interspinal level.
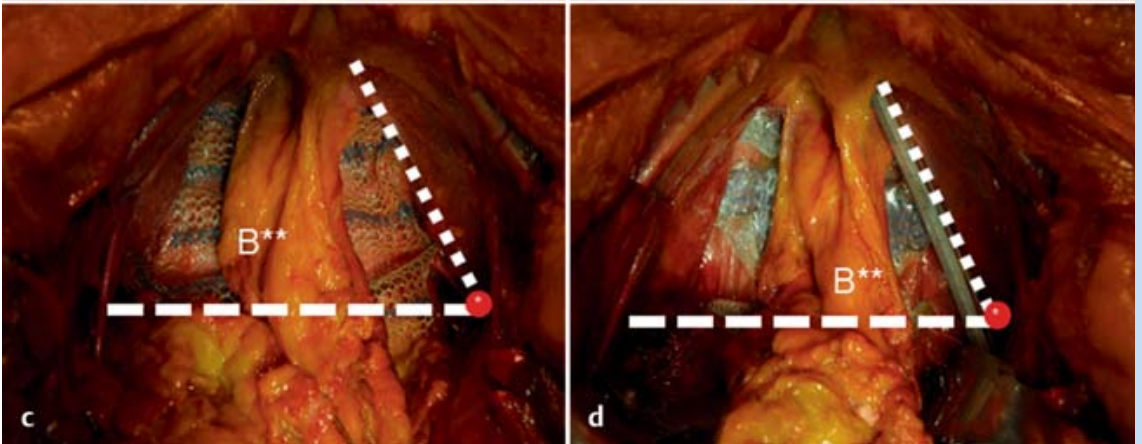

the pelvic floor with three arms on each side (six-point fixation). The anterior and middle pair of arms are placed via the transobturator route, and the cranial pair is additionally fixed sacrospinally and is diverted via the ischiorectal fossa. All meshes were removed after implantation and parameter documentation.

- Fig. 2 is a schematic drawing picturing each of the four products in relation to the ATFP and showing the ischial spine distance, and 0 Fig. 3 shows the implanted meshes in the female corpse.

\section{Results}

$\nabla$

The ATFP was fixed anteriorly $5 \mathrm{~mm}$ lateral to the symphysis. The distance between the drawn white line and the ischial spine was $105 \mathrm{~mm}$, and the distance from ischial spine to ischial spine was $131 \mathrm{~mm}$ in this cadaver. A bilateral separation of the pubocervical fascia was found, whereas the posterior part appeared to be intact. Its insertion point on the medial tip of the ischial spine was well developed. Altogether the endopelvic fascia covered an area of $54.6 \mathrm{~cm}^{2}$. The obturator nerve was located $35 \mathrm{~mm}$ from the white line.

The proximal fixation of the Avaulta ${ }^{\circledR}$ Anterior BioSynthetic Support System was found $20 \mathrm{~mm}$ from the ischial spine. The lateral edge was $10 \mathrm{~mm}$ from the ATFP. The proximal edge of the mesh did not reach the interspinal distance. For the Perigee ${ }^{\mathrm{TM}}$ Prolapse Repair System the distance to the ischial spine was $25 \mathrm{~mm}$, whereas the lateral distance was $20 \mathrm{~mm}$. In contrast to the previous mesh, the proximal edge reached the interspinal level. Since the Gynecare Prolift System was the largest implant, its proximal fixation was only $10 \mathrm{~mm}$ from the ischial spine. The lateral edge touched the ATFP, while the proximal edge reached the interspinal level. The proximal fixation of the Seratom ${ }^{\circledR}$ Prolapse Repair System was placed through the sacrospinous ligament, directly connecting the proximal edge and the fixation of the mesh close to the ischial spine and therefore reaching the interspinal level. Its lateral edge was $20 \mathrm{~mm}$ from the ATFP( Table 2, Fig. 2).
No differences in the positioning of the distal pair of arms were noted upon comparison of the distances of the perforation spots of the different introducer needles to the onset of the ATFP at the inner side of the pubis. For the proximal pair of arms, the Prolift introducer needle differed from the other products with regard to the distance to the ischial spine. While the interspinal level could not be reached for the proximal arm using the introducer instruments from Avaulta ${ }^{\circledR}$ and Perigee ${ }^{\mathrm{TM}}$ or for the middle arm using those from Seratom ${ }^{\circledR}$, it was possible to reach the interspinal level using the Prolift needle. However, for the Seratom ${ }^{\circledR}$ mesh, it was easily possible to reach the interspinal level using the instrument for the proximal third pair of arms (sacrospinal fixation via the fossa ischiorectalis).

Due to the anatomical structure of the obturator foramen and the hatchet- and helix-shaped introducer needles, it is impossible to reach above the interspinal level using the Avaulta ${ }^{\circledR}$, Perigee ${ }^{\mathrm{TM}}$ and Seratom ${ }^{\circledR}$ systems. A distance of $0 \mathrm{~mm}$ was measured between the lateral edges of the meshes to the ATFP only for the Prolift implant ( Table 2). The Prolift mesh appeared to be directly connected to the ATFP, yet in this position it was starting to wrinkle. With regard to the distance from the cranial edge of the meshes to the ischial spine, each of the implants reached the interspinal level except for the Avaulta ${ }^{\circledR}$ Anterior BioSynthetic mesh.

Table 2 Measured parameters in the anterior compartment for each mesh implant evaluated. ATFP = arcus tendineus fascia pelvis.

\begin{tabular}{|c|c|c|c|c|}
\hline & Perigee & Avaulta & Seratom & Prolift \\
\hline $\begin{array}{l}\text { Distance to ATFP } \\
(\mathrm{cm})\end{array}$ & 2 & 1 & 1.5 & 0 \\
\hline $\begin{array}{l}\text { Distance to ischial } \\
\text { spine }(\mathrm{cm})\end{array}$ & 2.5 & 4 & 0 & 1 \\
\hline $\begin{array}{l}\text { Area of the mesh } \\
\left(\mathrm{cm}^{2}\right)\end{array}$ & 34.5 & 19.25 & 48.1 & 112.75 \\
\hline
\end{tabular}




\section{Discussion}

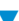

Due to the disappointing long-term results of traditional prolapse surgery and its high recurrence rates, various innovative techniques for reconstructing the pelvic floor have been introduced in the last decade $[1-4,8,18]$. The demand for new and reliable techniques made physicians search for alternatives. They pursued the idea of implanting alloplastic material (mesh) in women with advanced and symptomatic POP, but the question as to which mesh fits which woman has yet to be answered. In early attempts surgeons trimmed implants to fit each patient individually and attached them to the pelvic floor via a vaginal route using non-absorbable sutures. However, these techniques required an extensive vaginal dissection, often leading to intraor postoperative complications and an unsatisfactory surgical outcome $[26,27]$. The introduction of the transobturator approach marked the beginning of a new era in vaginal prolapse surgery. The mesh implant has arms to provide the support for the prolapsed organs that the patients' destroyed tissue can no longer offer. It became possible to repair defects in all three compartments of the pelvic floor and polypropylene implants became widely accepted in pelvic floor reconstruction [1,21]. In addition, abdominal sacrocolpopexy combined with paravaginal repair has significantly reduced the risk of further cystocele surgery compared to anterior colporrhaphy and sacrospinous colpopexy. The success rates for abdominal and paravaginal repairs are between 76 and 100\%. Randomized trials are lacking, however.

Several companies have launched various products. So far no reliable findings of the relative success rates of these products have been published, especially in terms of rates of recurrences or postoperative complications $[2,7]$. Nonetheless, the urogynecological surgeon is compelled to decide which mesh is best for which patient in order to achieve satisfying results. To sufficiently repair defects at levels I and II in the anterior compartment of the pelvic floor, implants have to be large enough to provide support and to cover the defect, but they may not be too large in order to avoid possible complications that could be caused by overlapping material.

We therefore set out to study four frequently employed mesh grafts in one female cadaver to find out whether each of the implants fits the pelvic floor of this cadaver equally well. We could show that the four meshes varied in size, application form and postsurgical placement.

The anatomical dissection conducted in this study suggests that the Avaulta ${ }^{\circledR}$ Anterior BioSynthetic Support System implant at that time was too small to cover large defects, especially level I defects. This implant achieved insufficient stabilisation of vaginal stump prolapse or enteroceles in the anterior compartment. For this reason, we would have recommended an enlargement of the implant, both in length and width, yet this product's successor, named Nuvia (by C. R. Bard, Inc.), had already been launched.

The sizes of the Perigee ${ }^{\mathrm{TM}}$ Prolapse Repair System and the Seratom ${ }^{\circledR}$ Prolapse Repair System are similar, but they differ in shape and placement position. In their final location both implants provide bladder support at the ischial spine level. The additional sacrospinous fixation provided by the Seratom ${ }^{\circledR}$ Prolapse Repair System might suggest stronger support in the case of advanced level I defects, providing the capacity to resist high pressure. However, an additional step involving perforation of the fossa ischiorectalis and the sacrospinal ligament is needed to securely place this extra pair of arms. Whether this will lead to higher intra- and postoperative complication rates, which could still be acceptable tak- ing the possibly lower recurrence rates at level I into consideration, has to be proven in further studies. It is remarkable that even the Perigee product was widely replaced by the Elevate Anterior \& Apical Prolapse Repair System for anterior and apical repair.

The first two implants were positioned satisfyingly beneath the bladder, but we detected a distance between their lateral edges and the ATFP, leaving a gap that could potentially cause recurrent lateral level II defects. Only the Gynecare Prolift System covered the entire surface of the EF, creating the opportunity for it to cover level I and II defects completely. Yet, due to its large size, it had to be folded to make it fit into this cadaver's pelvic floor. It can be imagined that this duplication of the mesh material in a vital situation might lead to later complications, although this has not yet been proven in clinical studies. For a smaller anatomy, this mesh implant seems oversized for it to be placed without any overlapping or trimming. At the current state of the art, an extended vaginal dissection is necessary to conduct a complete placement of this Prolift implant. The results of our anatomical study suggest that a reduction in this implant's size needs to be considered. At the time of publication, the Gynecare Prolift system was removed from the American and European markets.

Concerning the introducer needles, the level above the ischial spine can only be reached to achieve a high suspension of the proximal arm of the mesh by using the Gynecare Prolift System needle and the Serasis V instrument (via the fossa ischiorectalis). All the other introducer needles are limited in suspension due to their highly curved design. The anatomy of the obturator foramen, defined by the ramus inferior ossis pubis, the ramus superior ossis pubis and the corpus ossis ischii, limits the possibility of any of these needles puncturing the internal obturator muscle at the level of the ischial spine. Both the Avaulta needle as well as the Perigee and Serasis-TO SL introducer needles perforate the internal obturator membrane, with little difference between them. Concluding from this it can be said that curved introducer needles are not optimal for high level I and II suspension of the vagina, particularly given a long vagina. In these cases the risk of recurrent vaginal stump prolapse at level I appears highly possible.

The implantation of four meshes into a single cadaver, each implantation inevitably causing further damage to the cadaver's pelvic floor, can be seen as a limitation of this study. Yet the use of more cadavers would most likely only demonstrate the fact that meshes fit differently in different women. It would not prevent anatomical structures and tissue from being damaged after the first implantation, but this is still to be proven in further studies. Furthermore, a direct comparison of all four meshes is limited to the fact that three meshes with four fixational points and one mesh with six fixational points were chosen for this study.

Despite satisfying results being reported in the recent literature for recurrence rate and clinical outcome after mesh implants, there is a need for transobturator implants to be optimized [8]. Our observations describe the necessity of developing an optimally sized mesh as well as an appropriate introducer technique to provide sufficient vaginal levels I and II support in the anterior compartment. This and the profound knowledge of the patient's anatomical structures as well as the prolapse situation might reduce the risk of complications (e.g. erosions, dyspareunia, pelvic pain) often mentioned in combination with mesh surgery or help the physician understand the origin of postsurgical pain situations better. Yet prospective randomised long-term trials comparing different commercial products are necessary to validate 
this impression [15]. Additionally, maybe even the use of presurgical diagnostical tools such as 3D ultrasound or magnetic resonance imaging to document pelvic structures and distances could be useful for the physician to decide upon a suitable mesh implant. Although this, too, needs to be evaluated in further studies [28]. To develop more efficient meshes, the expert opinion of clinical urogynecologists should be involved in addition to the manufacturer's opinion.

It nevertheless seems clear that there is probably no ideally fitting mesh that suits every woman equally perfectly. To overcome this dilemma it seems necessary for urogynecological surgeons to have both great knowledge about the majority of products on the market and access to a broad variety of products. The surgeons would then be able, while in surgery, to decide which mesh to use after dissecting the vaginal wall and obtaining an anatomical overview of the patient's pelvic floor. We are conscious of the fact that this is unfortunately not always practicable in everyday clinical life.

\section{Conclusion for Practice}

$\nabla$

The urogynecologist needs profound knowledge of anatomical structures and the mesh implants accessible on the market.

\section{Acknowledgements \\ $\nabla$}

$\mathrm{KAB}$ received a research scholarship by the Faculty of Medicine of the University of Heidelberg to complete this work.

\section{Conflict of Interest}

$\nabla$

None.

\section{References}

1 Debodinance P, Berrocal J, Clave H et al. [Changing attitudes on the surgical treatment of urogenital prolapse: birth of the tension-free vaginal mesh]. J Gynecol Obstet Biol Reprod 2004; 33: 577-588

2 Nguyen JN, Burchette RJ. Outcome after anterior vaginal prolapse repair: a randomized controlled trial. Obstet Gynecol 2008; 111: 891898

3 Graefe F, Beilecke K, Tunn R. Vaginal vault prolapse following cystectomy: transvaginal reconstruction by mesh interposition. Int Urogynecol J 2012; Sep 7 [Epub ahead of print]

4 Graefe F, Marschke J, Dimpfl T et al. Vaginal vault suspension at hysterectomy for prolapse - myths and facts, anatomical requirements, fixation techniques, documentation and cost accounting. Geburtsh Frauenheilk 2012; 72:1099-1106

5 Naumann G, Kölbl H. Current developments and perspectives on the diagnosis and treatment of urinary incontinence and genital prolapse in women. Geburtsh Frauenheilk 2012; 72: 202-210

6 Chen L, Ashton-Miller JA, Hsu Y et al. Interaction among apical support, levator ani impairment, and anterior vaginal wall prolapse. Obstet Gynecol 2006; 108: 324-332
7 de Tayrac $R$, Devoldere G, Renaudie J et al. Prolapse repair by vaginal route using a new protected low-weight polypropylene mesh: 1-year functional and anatomical outcome in a prospective multicentre study. Int Urogynecol J Pelvic Floor Dysfunct 2007; 18: 251-256

8 Diwadkar GB, Barber MD, Feiner B et al. Complication and reoperation rates after apical vaginal prolapse surgical repair: a systematic review. Obstet Gynecol 2009; 113 (2 Pt 1): 367-373

9 de Tayrac RGA, Chauveaud A, Fernandez H. Tension-free polypropylene mesh for vaginal repair of anterior vaginal wall prolapse. J Reprod Med 2005; 50: 75-80

10 DeLancey J. Structural anatomy of the posterior pelvic compartment as it relates to rectocele. Am J Obstet Gynecol 1999; 180: 815-823

11 DeLancey JO. Anatomic aspects of vaginal eversion after hysterectomy. Am J Obstet Gynecol 1992; 166 (6 Pt 1): 1717-1724; discussion 17241728

12 Larson KA, Luo J, Yousuf A et al. Measurement of the 3D geometry of the fascial arches in women with a unilateral levator defect and "architectural distortion". Int Urogynecol J 2011; 23: 57-63

13 Chen L, Ashton-Miller JA, DeLancey JO. A 3D finite element model of anterior vaginal wall support to evaluate mechanisms underlying cystocele formation. J Biomech 2009; 42: 1371-1377

14 Larson KA, Luo J, Guire KE et al. 3D analysis of cystoceles using magnetic resonance imaging assessing midline, paravaginal, and apical defects. Int Urogynecol J 2011; 23: 285-293

15 Farthmann J, Watermann D, Niesel A et al. Lower exposure rates of partially absorbable mesh compared to nonabsorbable mesh for cystocele treatment: 3-year follow-up of a prospective randomized trial. Int Urogynecol J 2013; 24: 749-758

16 Moreno Sierra J, Prieto Nogal SB, Galante Romo MI et al. [New technique for the repair of anterior pelvic floor compartment defects using a synthetic implant with biological coverage: approach, fixation and transobturator anchoring]. Arch Esp Urol 2007; 60: 45-50

17 Sagsoz N, Ersoy M, Kamaci $M$ et al. Anatomical landmarks regarding sacrospinous colpopexy operations performed for vaginal vault prolapse. Eur J Obstet Gynecol Reprod Biol 2002; 101: 74-78

18 Sand PK, Koduri S, Lobel RW et al. Prospective randomized trial of polyglactin 910 mesh to prevent recurrence of cystoceles and rectoceles. Am J Obstet Gynecol 2001; 184: 1357-1362; discussion 13621364

19 Mostwin JL. Current concepts of female pelvic anatomy and physiology. Urol Clin North Am 1991; 18: 175-195

20 Pit MJ, De Ruiter MC, Lycklama A Nijeholt AA et al. Anatomy of the arcus tendineus fasciae pelvis in females. Clin Anat 2003; 16: 131-137

21 Reisenauer C, Kirschniak A, Drews $U$ et al. Anatomical conditions for pelvic floor reconstruction with polypropylene implant and its application for the treatment of vaginal prolapse. Eur J Obstet Gynecol Reprod Biol 2007; 131: 214-225

22 Deffieux X, de Tayrac R, Huel C et al. Vaginal mesh erosion after transvaginal repair of cystocele using Gynemesh or Gynemesh-Soft in 138 women: a comparative study. Int Urogynecol J Pelvic Floor Dysfunct 2007; $18: 73-79$

23 Jacquetin $B$, Cosson $M$. Complications of vaginal mesh: our experience. Int Urogynecol J Pelvic Floor Dysfunct 2009; 20: 893-896

24 Davila GWBM, Biller DH, Walters MD. Current concepts in pelvic anatomy and reconstructive surgery. Clev Clin J Med 2005; 72: 20-27

25 Albright TS, Gehrich AP, Davis GD et al. Arcus tendineus fascia pelvis: a further understanding. Am J Obstet Gynecol 2005; 193 (3 Pt 1): 677681

26 FitzGerald MP, Mollenhauer J, Bitterman Pet al. Functional failure of fascia lata allografts. Am J Obstet Gynecol 1999; 181: 1339-1344; discussion 1344-1346

27 Gandi SGR, Kwon C, Sand PK. A prospective randomized trial using solvent dehydrated fascia lata for the prevention of recurrent anterior vaginal wall prolapse. Am J Obstet Gynecol 2005; 192: 1649-1654

28 Dietz HP. The role of two- and three-dimensional dynamic ultrasonography in pelvic organ prolapse. J Minim Invasive Gynecol 2010; 17: 282-294 